\title{
Synergistic effects of Miconazole and Polymyxin B on microbial pathogens
}

\author{
Silvia Pietschmann • Katrin Hoffmann • Michael Voget • \\ Ulrich Pison
}

Accepted: 20 November 2008 / Published online: 16 December 2008

(C) The Author(s) 2008. This article is published with open access at Springerlink.com

\begin{abstract}
The therapeutic value of antibiotics depends on the susceptibility of the infecting microorganism and the pharmacological profile of the drugs. To assess the value of an antibiotic combination of polymyxin $\mathrm{B}$ and miconazole this study examined the in vitro synergistic potential of the two drugs on Gram-negative and Gram-positive bacteria and yeast. Antifungal and antibacterial activity was tested by minimum inhibitory concentration (MIC) of broth macrodilution and urea broth microdilution, by fluorescence microscopy and flow cytometry. Synergism was calculated using the fractional inhibitory concentration index (FICi). With Staphylococcus intermedius as target we found up to an eightfold reduction of the individual MICs when both drugs were combined. However, the FICi was 0.63 suggesting no real interaction between the two drugs. With Escherichia coli, Pseudomonas aeruginosa, and Malassezia pachydermatis as targets the antimicrobial drug combination reduced the MICs of polymyxin B and miconazole from fourfold to hundredfold resulting in FICi between 0.06 and 0.5 which defines a synergistic action. Thus, if polymyxin B and miconazole are combined their effect is greater than the sum of the effects observed with polymyxin B and miconazole independently, revealing bactericidal and fungicidal synergism. Our results indicate a strong therapeutic value for the combination of these antimicrobial agents against Gram-negative bacteria and yeast and a weaker value against Gram positive bacteria for clinical situations where these pathogens are involved.
\end{abstract}

Keywords Miconazole Polymyxin - Antibiotic synergism - Otitis externa

S. Pietschmann $\cdot$ U. Pison $(\bowtie)$

Charité - Universitätsmedizin Berlin, Klinik für Anästhesiologie und operative Intensivmedizin,

Campus Virchow-Klinikum, Augustenburger Platz 1, 13353 Berlin, Germany

e-mail: ulrich.pison@charite.de

K. Hoffmann

BAM, Bundesanstalt für Materialforschung und - prüfung, 12489 Berlin-Adlershof, Germany

M. Voget

ECON AG, Lübeck, Germany 


\section{Introduction}

Polymyxin B is an amphipatic cyclic decapeptide and cationic detergent with a broad antibiotic spectrum. It effects against Gram-negative bacteria such as Enterobacter, Escherichia coli, Pseudomonas spp., Salmonella spp. and Shigella spp and to a lesser extent, against Gram-positive bacteria as Staphylococcus spp. and Streptococcus spp. The bactericidal effect of polymyxin B relies on a dual mechanism of action. The sublethal action occurs as polymyxin B binds to the outer membrane of bacteria where it complexes avidly with lipopolysaccharides (Newton 1954) and disorganizes the whole outer membrane (Hancock 1984; Koike et al. 1968; Nikaido and Vaara 1985). This allows polymyxin B to enter the cytoplasmic membrane where it causes leakage of cytoplasmic components entailing the cells to die. It is noteworthy that the membrane permeability changes immediately on contact with the drug. The activity of polymyxin B is antagonized by $\mathrm{Mg}^{2+}$ and $\mathrm{Ca}^{2+}$ (Newton 1953), thus part of the action of this antibiotic is assumed as competitively displacing $\mathrm{Mg}^{2+}$ or $\mathrm{Ca}^{2+}$ from the negatively charged phosphate groups of membrane lipids. On parenteral administration polymyxin B is extreme nephrotoxic. However, as it completely lacks absorption from intact skin or mucous membrane and thus produces no systemic reaction, it is applied hitherto almost exclusively in topical therapy. Yet the polymyxins gain increasingly importance as reserve antibiotic. As the emergence of multiresistent Gram-negative bacteria pose serious clinical problems the polymyxins are recommended for severe systemic infections caused by bacteria that are resistant to other antibiotics (Ouderkirk et al. 2003; Pasquale and Tan 2005).

Miconazole, another antimicrobial active substance also aims at interacting with the cytoplasma membrane of microbiological pathogens. Miconazole belongs to the chemical class of imidazoles with a broad antifungal spectrum against most of the pathogenic fungi and Candida albicans. In vitro it shows an effect against some Gram-positive germs and acanthamoeba, too (Janssen and Van Bever 1979; McEvoy 1992). The drug permeates the chitin of the fungal cell wall and increases the membrane permeability to various intracellular substances (Sreedhara Swamy et al. 1974). Miconazole is known to interfere with the synthesis of fungal and bacterial lipid membranes as it restrains the synthesis of ergosterol which results in accumulation of toxic methylated sterol intermediates in membranes and subsequently in fungal cell growth arrests (Vanden Bossche et al. 1990). Another mode of miconazole antifungal action is the induction of reactive oxygen species in susceptible fungi leading to fungal cell death (Francois et al. 2006; Kobayashi et al. 2002). Side effects are rare if miconazole is applied topically (Sawyer et al. 1975) and to date no resistances are known in animals to miconazole (McEvoy 1992).

The application of both polymyxin B as an antibiotic and miconazole as a fungicide and Gram-positive antibacterial agent is common for those infections, where fungal and bacterial pathogens are aetiological. Both antimicrobial agents are proposed for the treatment of systemic mycosis and have been combined so far in topical preparations to provide a complementary antimicrobial spectrum for the prevention of minor wound infections and the treatment of dermatitis or otitis externa in veterinary medicine (Kiss et al. 1997; Rougier et al. 2005; Studdert and Hughes 1991). Organisms frequently isolated from these lesions include E. coli, P. aeruginosa, S. intermedius and the lipophilic yeast $M$. pachydermatis. The latter is a common inhabitant of the outer ear duct in dogs and cats but can also become an opportunistic pathogen, where an infectious state usually parallels a primary established illness.

The combination of antibiotics may reveal positive drug interactions such as an enhanced activity of the compounds or an increased antimicrobial spectrum. Several studies 
demonstrate an either synergistic or additive activity between the outer membrane pertubing agent polymyxin B and specific antibiotics (Rosenthal and Storm 1977), (Richards and Xing 1993), (Booth et al. 1994). Many studies have documented that polymyxin B nonapeptide which lacks bactericidal activity but has an outer membrane-permeabilization action preserved induces an increase in sensitivity to different antibiotics and other drugs (for review see (Vaara 1992)). The potentiation of the antifungal activity of tetracycline by polymyxin B through selective alteration of cell membrane permeability was reported, too (Schwartz et al. 1972), however there are contradictory results on this interaction. Also the lysis of Neisseria catarrhalis and other Gram-negative bacteria by lysozyme has been demonstrated in cells pretreated with polymyxin B sulfate. Since neither polymyxin nor lysozyme acting independently on the cells resulted in lysis, these results suggested that pre-treatment with the antibiotic increased the permeability of the cells or disorganized the cell wall and hence rendered the mucopolysaccharide substrate accessible to the action of the enzyme (Warren et al. 1957). Furthermore the antibacterial activity of a combination of miconazole and/or bacitracin with polymyxin B against Staphylococcus aureus and E. coli was higher than the sum of the effects observed with the two drugs independently (Cornelissen and Van den Bossche 1983). A synergy in antifungal activity against Candida albicans was reported as well when polymyxin B was combined with amphotericin B, ketoconazole and miconazole (Moneib 1995) and miconazole applied together with benzoylperoxide markedly increased the bactericidal activity against Staphylococcus spp. and Propionibacterium acnes (Vanden Bossche et al. 1982).

It was the objective of the study to verify the presumed synergistic effect of polymyxin $\mathrm{B}$ and miconazole with both bacteria and yeast. We compared the in vitro activity of polymyxin B and miconazole as single substances and in combination against E. coli, $P$. aeruginosa, S. intermedius and $M$. pachydermatis. Bacterial viability was assessed by means of a standard MIC test, fluorescence microscopy and flow cytometry while yeast susceptibility was evaluated using an urea broth microdilution method.

\section{Materials and methods}

\section{Antimicrobial agents}

Freshly prepared solutions of polymyxin B sulfate (Sigma-Aldrich, Taufkirchen, Germany) in deionized water or miconazole nitrate salt (Sigma-Aldrich) dissolved in $25 \%(\mathrm{v} / \mathrm{v})$ ethanol and $75 \%(\mathrm{v} / \mathrm{v})$ polyethylenglycol 400 while heating for $2 \mathrm{~h}$ at $60^{\circ} \mathrm{C}$ were filter sterilized (pore size $0.2 \mu \mathrm{m}$ ) prior use.

\section{Susceptibility testing}

For examination of antibiotic susceptibility the tube dilution test was applied. The quality control strains E. coli (ATCC 25922), P. aeruginosa (ATCC 27853) and S. intermedius (ATCC 5739) were used for determination of MICs. For the content of selected tubes from susceptibility testing we determined the minimal bactericidal concentration (MBC) by endpoint colony counting of bacteria on Mueller-Hinton agar. For pre-trial MIC E. coli strain XL-1 (Stratagene) was used. E. coli and P. aeruginosa were cultivated in MuellerHinton Broth (Merck/VWR, Darmstadt, Germany; if not mentioned otherwise, all chemicals were obtained from Merck/VWR). S. intermedius was propagated either in corynebacteria nutrient $(1 \%$ casein peptone, tryptic digest, Difco/BD, Heidelberg, Germany, 
$0.5 \%$ yeast extract, Difco/BD, $0.5 \%$ glucose and $0.5 \% \mathrm{NaCl}$ ) or in Mueller-Hinton Broth. Bacteria from frozen stocks were subcultured three times on agar plates. Then two single colonies were picked each to inoculate a liquid overnight culture. The bacterial cultures were grown to early $\log$ phase at $37^{\circ} \mathrm{C}$ aerobically by shaking in a reciprocating shaker. Bacterial inoculum was prepared in Mueller-Hinton Broth at $2 \times 10^{6}$ colony forming units $(\mathrm{CFU}) / \mathrm{ml}$ to give a final concentration of $2 \times 10^{6} \mathrm{CFU}$. To each tube $5.0 \mathrm{ml}$ of bacterial culture, $4.0 \mathrm{ml}$ of growth medium, $0.5 \mathrm{ml}$ of a polymyxin B dilution or $0.5 \mathrm{ml}$ of a dilution of miconazole was added. Each $0.5 \mathrm{ml}$ of dilution of polymyxin B and miconazole was also added in combination to $5.0 \mathrm{ml}$ of bacterial culture and $4.0 \mathrm{ml}$ of growth medium. Samples with single active substance or controls were adjusted to a total volume of $10.0 \mathrm{ml}$ with $0.5 \mathrm{ml}$ sterile deionized water. Solutions of polymyxin B or miconazole consisted of $\log 10$ dilution steps between 750 and $0.075 \mu \mathrm{g} / \mathrm{ml}$ and $\log 2$ dilution steps between 750 and $0.046 \mu \mathrm{g} / \mathrm{ml}$. For all experiments freshly prepared antimicrobial solutions were used.

Bacterial cultures without active substance $(\mathrm{C}$, bacterial inoculum and growth medium) and bacterial cultures with $0.5 \mathrm{ml}$ solvent (L, bacterial inoculum, growth medium and solvent containing $25 \%$ ethanol and $75 \%$ polyethylenglycol 400 , which was also heated to $60^{\circ} \mathrm{C}$ for $2 \mathrm{~h}$ ) served as growth controls. Also a sterility control tube (M, growth medium) was included into each MIC test. The cultures were incubated for $18 \mathrm{~h}$ at $37^{\circ} \mathrm{C}$ under aerophilic conditions. After $18 \mathrm{~h}$ of incubation the MIC was read as the lowest drug concentration that inhibited bacterial growth.

Each test was performed 5 times. For the first clear tube containing both antimicrobial agents the fractional inhibitory concentration (FIC) was calculated as follows: FIC of drug $\mathrm{A}\left(\mathrm{FIC}_{\mathrm{A}}\right)=\mathrm{MIC}$ of drug $\mathrm{A}$ in combination/MIC of drug $\mathrm{A}$ alone, $\mathrm{FIC}$ of drug $\mathrm{B}\left(\mathrm{FIC}_{\mathrm{B}}\right)=$ $\mathrm{MIC}$ of drug $\mathrm{B}$ in combination/MIC of drug B alone. FIC Index (FICi), calculated as the sum of each FIC, was interpreted as follows: $\mathrm{FICi} \leq 0.5=$ synergy, $\mathrm{FICi}>4.0=$ antagonism and $\mathrm{FICi}>0.5-4=$ no interaction (Odds 2003).

Christensen's urea broth microdilution method

The Christensen's urea broth microdilution method (Nakamura et al. 2000) (Rincón et al. 2006) was applied to assay the antifungal activities of polymyxin B and miconazole alone and in combination against $M$. pachydermatis. With this test fungal cell activity is measured. The mechanism is relying upon the release of ammonia during urea hydrolysis to change the $\mathrm{pH}$ of the medium, converting the yellow phenol red indicator to pink (Roberts et al. 1978).

Malassezia. pachydermatis reference strain (CBS 1879) was propagated at $35^{\circ} \mathrm{C}$ on modified Leeming and Notman slants (Leeming and Notman 1987) containing 1\% bacteriological peptone (Difco/BD), 1\% glucose, $0.2 \%$ yeast extract (Difco/BD), $0.8 \%$ ox bile (Difco/BD), desiccated, 1\% (v/v) glycerol (Sigma-Aldrich, Taufkirchen, Germany), glycerol monostearate (Elbe Fetthandel GmbH, Geesthacht, Germany), 0.5\% (v/v) Tween 60 (Sigma-Aldrich), 2\% olive oil (Sigma-Aldrich) and 1.5\% agar (Sigma-Aldrich). The isolate was subcultured every 2 weeks more than three times before use. The colonies were collected by scraping, suspended with sterile $0.04 \%$ Tween 80 in sterile deionized water $(\mathrm{pH}$ 7.4) with a glass homogenizer and the suspension was adjusted to an OD at 530 of 0.42 to $0.43\left(\sim 1 \times 10^{6} \mathrm{CFU} / \mathrm{ml}\right)$. Solutions of polymyxin B or miconazole consisted of $\log 2$ dilution steps between 187.5 and $0.01 \mu \mathrm{g} / \mathrm{ml}$. The urea broth microdilution method was performed in 96-well microtiter plates. Christensen's urea broth contained $0.1 \%$ peptone (Difco/BD), $0.0012 \%$ phenol red (Sigma-Aldrich), $0.5 \%$ sodium chloride, $0.2 \%$ monopotassium phosphate, $0.1 \%$ glucose, $2 \%$ urea, supplemented with $0.1 \%$ Tween 80 (Sigma-Aldrich) 
and $0.5 \%$ Tween 40 (Sigma-Aldrich), $\mathrm{pH}$ 5.2. We added to each well $100 \mu$ l Christensen's urea broth, $50 \mu$ l yeast suspension, $25 \mu l$ test drug and $25 \mu \mathrm{l}$ sterile deionized water or $50 \mu \mathrm{l}$ test drug and no water if both test drugs were used in combination. The final inoculum of Malassezia pachydermatis in each well was $\sim 0.25 \times 10^{5} \mathrm{CFU} / \mathrm{ml}$.

The test drugs were arranged in twofold dilution from left to right and in triplicate. The 96-well microtiter plates were sealed with Parafilm ${ }^{\circledR} \mathrm{M}$ and incubated at $35^{\circ} \mathrm{C}$ for $48 \mathrm{~h}$. The results were evaluated visually. The MICs were defined as the lowest drug concentration at which there was complete inhibition of growth and no colour change of the media was observed.

\section{Fluorescence microscopy}

To differentiate live bacteria from dead ones, bacteria were stained in suspension with the Live/Dead BacLight Bacterial Viability Kit (Molecular Probes, Mobitek, Germany). The SYTO 9 nucleic acid stain solution (excitation/emission maxima 480/500) is cell-permeable and stains RNA and DNA in both live and dead bacterial cells green. Propidium iodide (PI, excitation/emission maxima 490/635) penetrates only cells with damaged membranes, thus stains the cells red. Logarithmically growing bacteria cultures were incubated with dilutions of polymyxin $\mathrm{B}$, miconazole or with both substances in combination for $18 \mathrm{~h}$ at $37^{\circ} \mathrm{C}$ while agitation. Each $1.5 \mathrm{ml}$ bacterial sample was concentrated by centrifugation at $10.000 \times \mathrm{g}$ for 5 minutes at room temperature and washed once with $0.9 \% \mathrm{NaCl}$. The supernatant was removed and the pellet resuspended in $150 \mu \mathrm{l} 0.9 \% \mathrm{NaCl}$. SYTO9 dye $(3.34 \mathrm{mM}$ in anhydrous dimethylsulfoxide, DMSO) and PI dye (20 $\mathrm{mM}$ in anhydrous DMSO) were combined 1:1 and mixed thoroughly. To each $150 \mu \mathrm{l}$ of concentrated bacterial suspension $0.8 \mu \mathrm{l}$ of the dye mixture was added, mixed and incubated in the dark at room temperature for 15 minutes. Five $\mu 1$ of the stained bacterial suspension was transferred onto a $24 \times$ $46 \mathrm{~mm}$ coverslip and visualized directly using a confocal laser scanning microscope Olympus FluoView ${ }^{\mathrm{TM}}$ FV1000 (Olympus, Hamburg, Germany). Confocal images were obtained with an argon ion laser as excitation source (excitation wavelength of $488 \mathrm{~nm}$; $1.3 \%$ laser power), which was reflected by an dichroic mirror (DM 351/488/543) and focused onto the sample through an oil immersion objective (Olympus Planapochromat $60 \mathrm{x}$, numerical aperture $\mathrm{NA}=1.35$. Detection channels were set to fluorescein isothiocyanate (FITC, maximum emission $515 \mathrm{~nm}$ ) and Alexa 594 (maximum emission $618 \mathrm{~nm}$ ). The live (green fluorescent) and dead (red fluorescent) cells are shown separately and as an overlay with FITC and Alexa 594 bandpass filters. For virtual magnification of bacteria a 3-fold digital zoom was applied.

Bacteria were also visualized with a Zeiss Axiovert 10 microscope (Zeiss, Oberkochen, Germany) equipped with filter set 00 (BP530-585, FT600, LP615) and filter set 09 (BP450490, FT 510, LP515).

\section{Flow cytometry}

Data were acquired with a FC 500 flow cytometer (Beckman Coulter) with an argon ion laser at $488 \mathrm{~nm}$ and $20 \mathrm{~mW}$ output. Data acquisition and analysis were controlled using Cytomics software. The emission light path contained a $488 \mathrm{~nm}$ blocking filter, a 525 bandpass filter before the photomultiplier 1 (PMT) and a $620 \mathrm{~nm}$ bandpass filter before the PMT3. The density of the bacterial suspensions was $1 \times 10^{6} \mathrm{CFU} / \mathrm{ml}$. Bacterial suspensions were incubated with dilutions of polymyxin $\mathrm{B}$, miconazole or both substances in combination for $18 \mathrm{~h}$ at $37^{\circ} \mathrm{C}$ at aerobic conditions. The cells were harvested by 
centrifugation at $10.000 \times \mathrm{g}$ for $15 \mathrm{~min}$, washed once in $0.9 \% \mathrm{NaCl}$ and diluted to an $\mathrm{OD}$ at $670 \mathrm{~nm}$ of 0,03 with $0.9 \% \mathrm{NaCl}$. Then $6 \mu \mathrm{l}$ of $1: 1 \mathrm{SYTO} 9$ and PI dye mixture was added to $2 \mathrm{ml}$ of diluted bacterial suspension, mixed well and incubated in the dark at room temperature for $15 \mathrm{~min}$. Populations of bacteria were discriminated as two regions of the log-integrated red-fluorescence (FL3) versus log-integrated green fluorescence (FL1) plot. The percentage of bacteria found within the region identified as those with the "live" cell population was used to estimate the percentage of viable organisms. Using the known viability (proportion of "live" to "killed" bacteria) and measured viability (measured \% live bacteria $=[\#$ of bacteria in the "live" region/\# of bacteria in the "live"+"dead" region] $\times 100$ ) and a least-squares fit extrapolated to the $100 \%$ "live" point the percent component of dead bacteria in the "live" cell population was estimated.

\section{Results}

Antibiotic susceptibility

MICs of two antimicrobials given as single drug each or in combination were determined. The results of the susceptibility tests are summarized in Table 1. E. coli strain XL-1 was susceptible to $7.5 \mu \mathrm{g} / \mathrm{ml}$ polymyxin $\mathrm{B}$, but was susceptible to a concentration of polymyxin $\mathrm{B}$ as low as $0.07 \mu \mathrm{g} / \mathrm{ml}$ if combined with $0.07 \mu \mathrm{g} / \mathrm{ml}$ miconazole $(\mathrm{FICi}=0.01)$. No effect on bacterial growth was observed it miconazole was applied alone. The E. coli quality control strain was susceptible to $2.93 \mu \mathrm{g} / \mathrm{ml}$ polymyxin B if given as a single antibiotic and to a concentration of $0.18 \mu \mathrm{g} / \mathrm{ml}$ if applied together with the identical concentration of miconazole $(\mathrm{FICi}=0.06)$. As well miconazole alone could not inhibit $E$. coli growth. $P$. aeruginosa was susceptible to $0.73 \mu \mathrm{g} / \mathrm{ml}$ polymyxin $\mathrm{B}$ and showed no effect to miconazole. If polymyxin $\mathrm{B}$ acted together with miconazole each drug was inhibitory at a concentration of $0.18 \mu \mathrm{g} / \mathrm{ml}(\mathrm{FICi}=0.25)$. Thus, when polymyxin $\mathrm{B}$ and miconazole were applied in combination they reproducibly showed a clear synergistic antibacterial effect against the Gram-negative strains tested. The Gram-positive $S$. intermedius was susceptible to $0.73 \mu \mathrm{g} / \mathrm{ml}$ miconazole and to $2.93 \mu \mathrm{g} / \mathrm{ml}$ polymyxin B. If identical concentrations of polymyxin $\mathrm{B}$ and miconazole were combined a twofold lower dose of miconazole and an

Table 1 In vitro susceptibilities of bacterial and yeast strains

\begin{tabular}{|c|c|c|c|}
\hline Germ strain & $\begin{array}{l}\text { Miconazole MIC* } \\
\text { Range (Mode) }\end{array}$ & $\begin{array}{l}\text { Polymyxin B MIC } \\
\text { Range (Mode) }\end{array}$ & $\begin{array}{l}\text { Miconazole+ Polymyxin B } \\
\text { MIC Range (Mode) FICi }\end{array}$ \\
\hline E. coli $\mathrm{XL}-1^{\mathrm{a}}$ & no inhibition & 7.50 & $<0.070 .01$ \\
\hline E. coli $(\mathrm{ATCC} 25922)^{\mathrm{b}}$ & no inhibition & $0.73-2.93(2.93)$ & $0.18-1.46(0.18) 0.06$ \\
\hline P. aeruginosa (ATCC 27853) & no inhibition & 0.73 & $0.18-0.37(0.18) 0.25$ \\
\hline S. intermedius (ATCC 5739) & $0.37-7.5(0.73)$ & $2.93-7.50(2.93)$ & $0.37-0.75(0.37) 0.63$ \\
\hline M. pachydermatis $(\mathrm{CBS} 1879)^{\mathrm{c}}$ & $2.92-5.85(2.92)$ & $2.92-23.43(2.92)$ & $0.37-1.46(0.73) 0.50$ \\
\hline
\end{tabular}

*MIC, minimal inhibitory concentration, given in $\mu \mathrm{g} / \mathrm{ml}$; $\mathrm{FICi}$, fractional inhibitory concentration index, given as described in Material and methods

a Results of 2 repeated experiments on different days

b Results of 5 repeated experiments on different days

c Results of 5 repeated experiments on different days with triplicates of each sample 
eightfold lower dose of polymyxin B was effective for growth inhibition (MIC $=0.37 \mu \mathrm{g} / \mathrm{ml}$, $\mathrm{FICi}=0.63$ ). According to a recent revision of the definition of synergy a $\mathrm{FICi}>0.5-4.0$ is interpreted as 'no interaction' (Odds 2003). Therefore the resulting FICi of 0.63 indicates there is no interaction between both drugs if active against $S$. intermedius.

The mean antifungal activies of miconazole and polymyxin B against $M$. pachydermatis were measured using an urease method, as shown in Fig. 1. If we compared the wells

Fig. 1 Antifungal MIC determination using Christensen's urea broth microdilution method. Urea hydrolysis by $M$. pachydermatis in microtiter test plates. A positive test is read as a colour change from yellow to pink. The test drugs were arranged in twofold dilution from left to right (row $1-12,188 \mu \mathrm{g} / \mathrm{ml}$ to $0.09 \mu \mathrm{g} / \mathrm{ml}$ ) and in triplicate (rows A, B, C). D1, D4, E1, E4, $\mathrm{F} 1$ and $\mathrm{F} 4$ represent negative controls (growth medium with distilled water). D2, E2 and F2 are positive controls (all compounds without test drug). D3, E3, F3 contain the solvent of miconazole (polyethylenglycol 400 with ethanol), growth medium and yeast cells as a growth control.

From top to bottom: Plate with dilutions of polymyxin B. Plate with dilutions of miconazole. Plate with dilutions of miconazole plus polymyxin $\mathrm{B}$

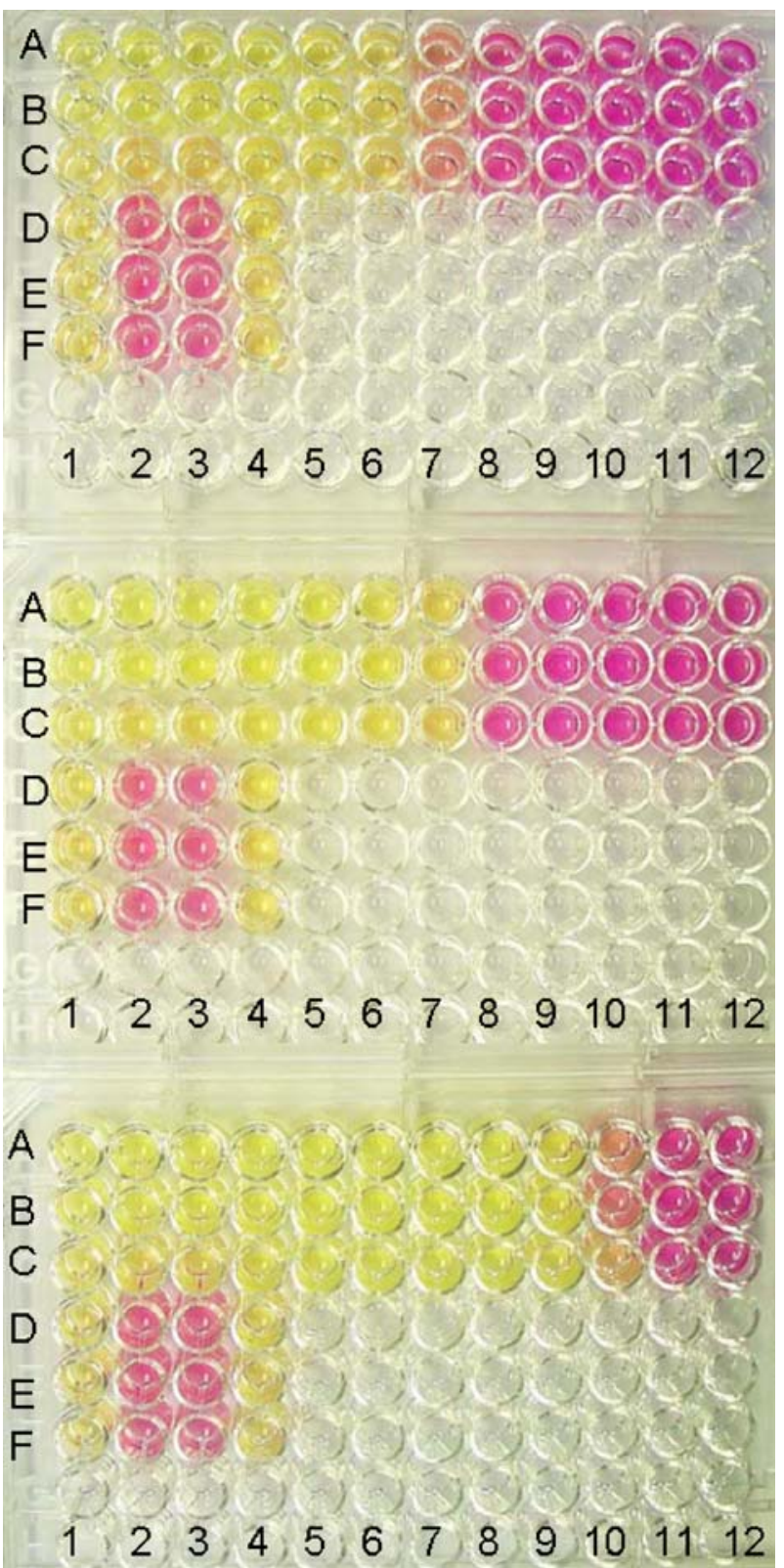


containing the growth media without $M$. pachydermatis to drug-containing wells with yeast cells we found a MIC of $2.92 \mu \mathrm{g} / \mathrm{ml}$ for miconazole and for polymyxin B as well. If both antimicrobial agents were given in combination susceptibility of $M$. pachydermatis changed to a $\mathrm{MIC}$ of $0.73 \mu \mathrm{g} / \mathrm{ml}(\mathrm{FICi}=0,50)$, which indicates a synergistic response.

\section{Confocal laser scanning microscopy and fluorescence microscopy}

Qualitative differentiation of live and dead bacteria was done by confocal laser scanning microscopy (CLSM). CLSM is non-destructive and makes it possible to analyze live biological samples. Living and dead microorganism could be detected in situ using an appropriate staining method. Cultures of $S$. intermedius were incubated with different concentrations of polymyxin B and miconazole and stained subsequently with SYTO9 and PI dye. The analysis of bacteria by CLSM allowed the generation of images where the fluorescence of only one dye was visualized. Using narrow bandpass filters the fluorescence of one or the other dye was eliminated respectively. Imaging from the green emission only detects the living green cells and imaging from the red emission detects the dead red cells solely. The left and the right pictures of Fig. 2 represent identical shots of bacterial $S$. intermedius suspensions. The untreated bacteria (2-1 and 2-2) with only a few red (dead) cells are shown in (2-2). After $18 \mathrm{~h}$ of incubation with $75 \mu \mathrm{g} / \mathrm{ml}$ miconazole (2-3 and 2-4) more than $50 \%$ of the cells became red and are assumed to be dead or in the process to die (2-4). The application of an identical concentration of polymyxin B (2-5 and 2-6) resulted in about 50\% red cells (2-6). A tenfold lower concentration of both antimicrobials applied in combination (2-7 and 2-8) revealed strikingly more red cells (2-8) than miconazole or polymyxin B generated when applied alone (2-4 and 2-6, respectively).

To exhibit both dyes within one picture an overlay of two images, each detected with a narrow fluorescence wavelength range was made. Thus the living and dead cells of Fig. 2 are visualized within one image (Fig. 3). Consequently, using CLSM and the Live/Dead BacLight Bacterial Viability Kit the live and the dead organisms can be differentiated and determined even after they had been mixed. Furthermore it was possible to evaluate the antibiotic effect visually.

Live and dead bacteria were also visualized with an inverted fluorescence microscope after staining with SYTO9 and PI dye. With this method green and red cells are discriminated using alternately a filter set for FITC and other green fluorochromes or a filter set for red fluorochromes. Owing to the fact that these bandpass filters are not as narrow as in CLSM the pictures representing the green fluorescence also show red cells in the background. If red cells overlay green cells these cells are visualized yellow. Figure 4 demonstrates a qualitative analysis of antimicrobial action against E. coli and P. aeruginosa after $18 \mathrm{~h}$ of antibiotic action. Cells without treatment show very few red bacteria (a, e); following application of $0.73 \mu \mathrm{g} / \mathrm{ml}$ miconazole alone about $10 \%$ cells are scored as dead (red) (b, f). An identical concentration of solitary polymyxin B gave rise to about $30 \%$ dead (red) cells (c, g) whereas a fourfold lower concentration of each drug, if applied in combination, produced a comparable biological effect $(\mathrm{d}, \mathrm{h})$. As a result using this method the antibiotic effectiveness can be quickly evaluated qualitatively as a ratio of live and dead cells within a given population. Visual examination of bacterial cells has approved an enhanced bacterial killing if miconazole and polymyxin B are applied together.

Flow cytometry

Exemplified on two bacterial strains we analysed E. coli and P. aeruginosa by flow cytometry after antibiotic exposure and staining with the Live/Dead BacLight Bacterial 
Fig. 2 Confocal laser scanning microscopy. Samples of

$S$. intermedius after treatment for $18 \mathrm{~h}$ with polymyxin $\mathrm{B}$, miconazole or with both polymyxin $\mathrm{B}$ and miconazole in combination. The cells were stained with SYTO 9 and PI. The left (green) pictures are generated using a FITC bandpass filter and visualize only the living cells, whereas the right (red) pictures are generated from identical presentations using an Alexa 594 bandpass filter to detect the dead cells exclusively.

From top to bottom: Untreated bacteria (2-1 and 2-2). Bacteria treated with $75 \mu \mathrm{g} / \mathrm{ml}$ miconazole (2-3 and 2-4). Bacteria treated with $75 \mu \mathrm{g} / \mathrm{ml}$ polymyxin B (2-5 and 2-6). Bacteria treated with $7.5 \mu \mathrm{g} / \mathrm{ml}$ miconazole plus $7.5 \mu \mathrm{g} / \mathrm{ml}$ polymyxin B (2-7 and 2-8)
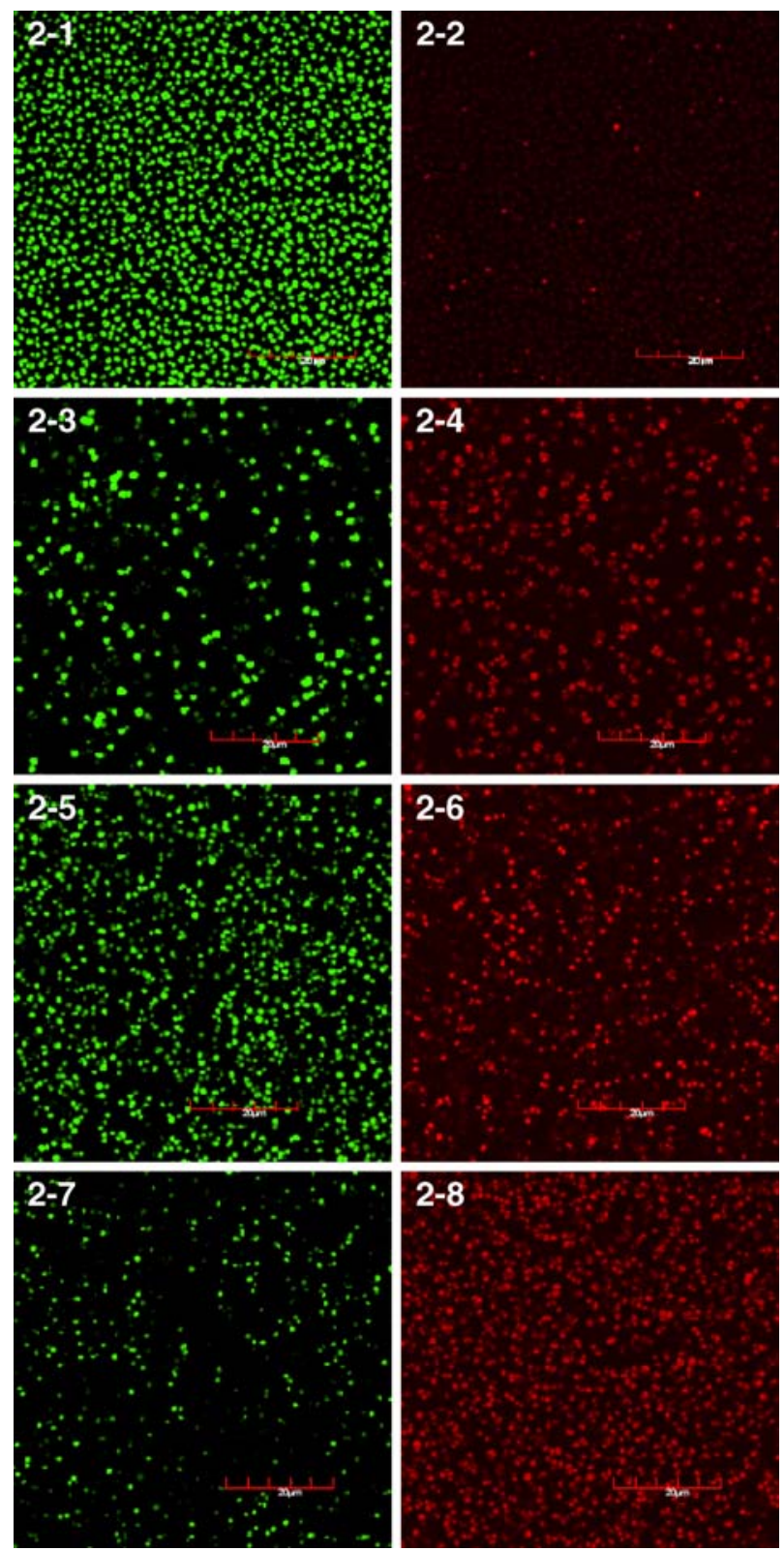

Viability Kit. The percentage of live cells in the population could be calculated by the standard curve shown in Fig. 5. For E. coli the rate of live cells was $87 \%$ and for $P$. aeruginosa we identified $98 \%$ live cells within the population investigated.

When E. coli was treated with $2.93 \mu \mathrm{g} / \mathrm{ml}$ of miconazole, a dead rate of $10.9 \%$ was measured which is in the dimension of the normal proportion of dead cells within a poulation. On the other hand $2.93 \mu \mathrm{g} / \mathrm{ml}$ of polymyxin B resulted in killing of $45.8 \% \mathrm{E}$. coli bacteria. Both drugs in combination each at a concentration of $1.46 \mu \mathrm{g} / \mathrm{ml}$ killed $72.0 \%$ 
Fig. 3 Overlay pictures of live (green fluorescent) and dead (red fluorescent) $S$. intermedius bacteria are shown using a confocal laser scanning microscope.

Untreated bacteria (3-1). Bacteria treated with $75 \mu \mathrm{g} / \mathrm{ml}$ miconazole (3-2). Bacteria treated with $75 \mu \mathrm{g} / \mathrm{ml}$ polymyxin B (3-3). Bacteria treated with $7.5 \mu \mathrm{g} / \mathrm{ml}$ miconazole plus $7.5 \mu \mathrm{g} / \mathrm{ml}$ polymyxin B (3-4)
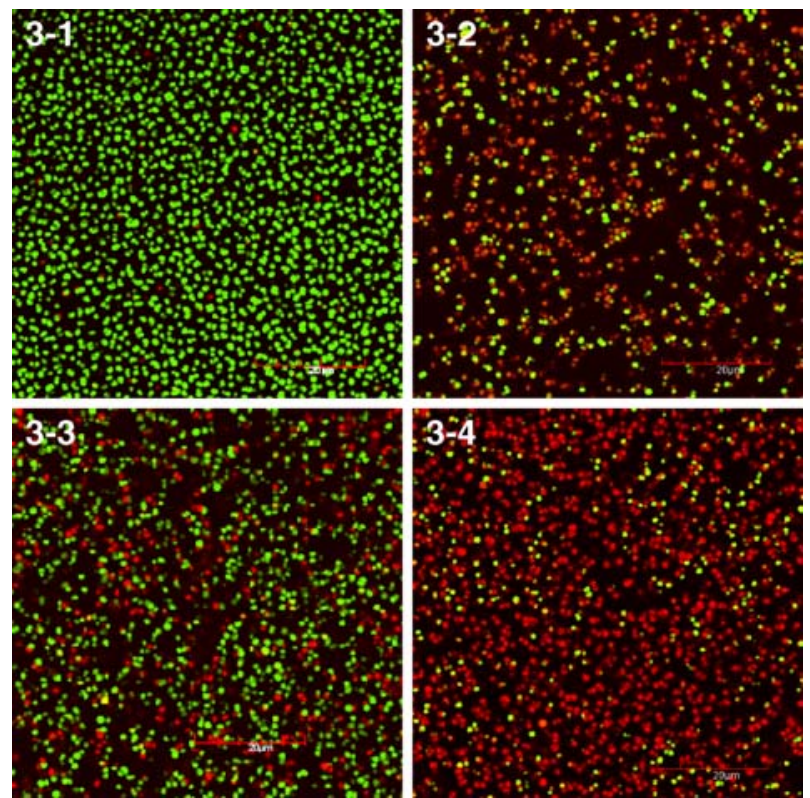

of all cells within $18 \mathrm{~h}$ (Fig. 6). Following polymyxin B and miconazole application for $18 \mathrm{~h}$ flow cytometric analysis of the vitality of $P$. aeruginosa revealed that less cells were affected. After application of $5.86 \mu \mathrm{g} / \mathrm{ml}$ miconazole $8.1 \%$ of the bacterial population stained red and therefore was counted dead while $5.86 \mu \mathrm{g} / \mathrm{ml}$ of polymyxin B resulted in only $5.7 \%$ dead cells. The combination of $2.93 \mu \mathrm{g} / \mathrm{ml}$ miconazole with $2.93 \mu \mathrm{g} / \mathrm{ml}$ polymyxin B stained $27 \%$ of the cells red (results are not shown) which is decidedly a lower rate of dead cells than that found with E. coli. Our results show that the survival rate for the determination of bactericidal efficacy of antibacterial agents can be measured by FACS analysis. Against E. coli and P. aeruginosa we could demonstrate an enhanced effect when both the drugs miconazole and polymyxin $\mathrm{B}$ act in combination.

\section{Discussion}

This study was conducted to evaluate the net results of the in vitro interactions against bacteria and yeast between polymyxin B and miconazole using different methods. While for decades miconazole has been successfully applied as a very potent antifungal drug polymyxin B has not been used over the past years but in veterinary medicine because less toxic antimicrobials are available. Yet bacteria that are resistant to aminoglycosides, betalactams and fluoroquinolones are becoming more common and these germs are often susceptible to the polymyxins.

The tube dilution test for the determination of MICs against the two strains of E. coli, against $P$. aeruginosa and against $S$. intermedius demonstrated that all the bacteria were susceptible to polymyxin B. Data of our MIC tests are consistent with previous reports where the MIC against $E$. coli was in the range of 0.4 to $37 \mu \mathrm{g} / \mathrm{ml}$ (Kucers 1997). Against $P$. aeruginosa polymyxin $\mathrm{B}$ exhibited excellent potency. We found $P$. aeruginosa to be more sensitive to polymyxin B compared to reported MICs which range from 1.2 to 
$33.3 \mu \mathrm{g} / \mathrm{ml}$ (Kucers 1997). Little information is available about the susceptibility of $S$. intermedius to different antimicrobial agents. Though many authors quote the antimicrobial activity of polymyxin B to be restricted to Gram-negative bacteria (e.g. Chambers 2001), several studies showed the effectiveness of polymyxin B against $S$. intermedius. On the other hand a low susceptibility of $S$. intermedius strains isolated from dogs to polymyxin B was also reported (Junco and Barrasa 2002). In our study polymyxin was quite effective against $S$. intermedius, our tests revealed a MIC of $5.21 \mu \mathrm{g} / \mathrm{ml}$ which is in a magnitude comparable to the MICs of other bacterial strains investigated. It is noteworthy that

Fig. 4 Fluorescence microscopy of $E$. coli $(\mathbf{a}, \mathbf{b}, \mathbf{c}, \mathbf{d})$ and $P$. aeruginosa $(\mathbf{e}, \mathbf{f}, \mathbf{g}, \mathbf{h})$, treated with either polymyxin B, miconazole or with both substances in combination for $18 \mathrm{~h}$. Cells were then stained with SYTO9 and PI. Identical pictures of bacterial suspensions are generated with a green (left pictures) or red (right pictures) filter set. The red stained cells represent bacteria with damaged membranes and the green cells denote those with intact membranes. Untreated bacterial cells (a, e), bacteria treated with $0.73 \mu \mathrm{g} / \mathrm{ml}$ miconazol (b, f), with $0.73 \mu \mathrm{g} / \mathrm{ml}$ polymyxin B $(\mathbf{c}, \mathbf{g})$ and with $0.18 \mu \mathrm{g} / \mathrm{ml}$ miconazole plus $0.18 \mu \mathrm{g} / \mathrm{ml}$ polymyxin $\mathrm{B}(\mathbf{d}, \mathbf{h})$
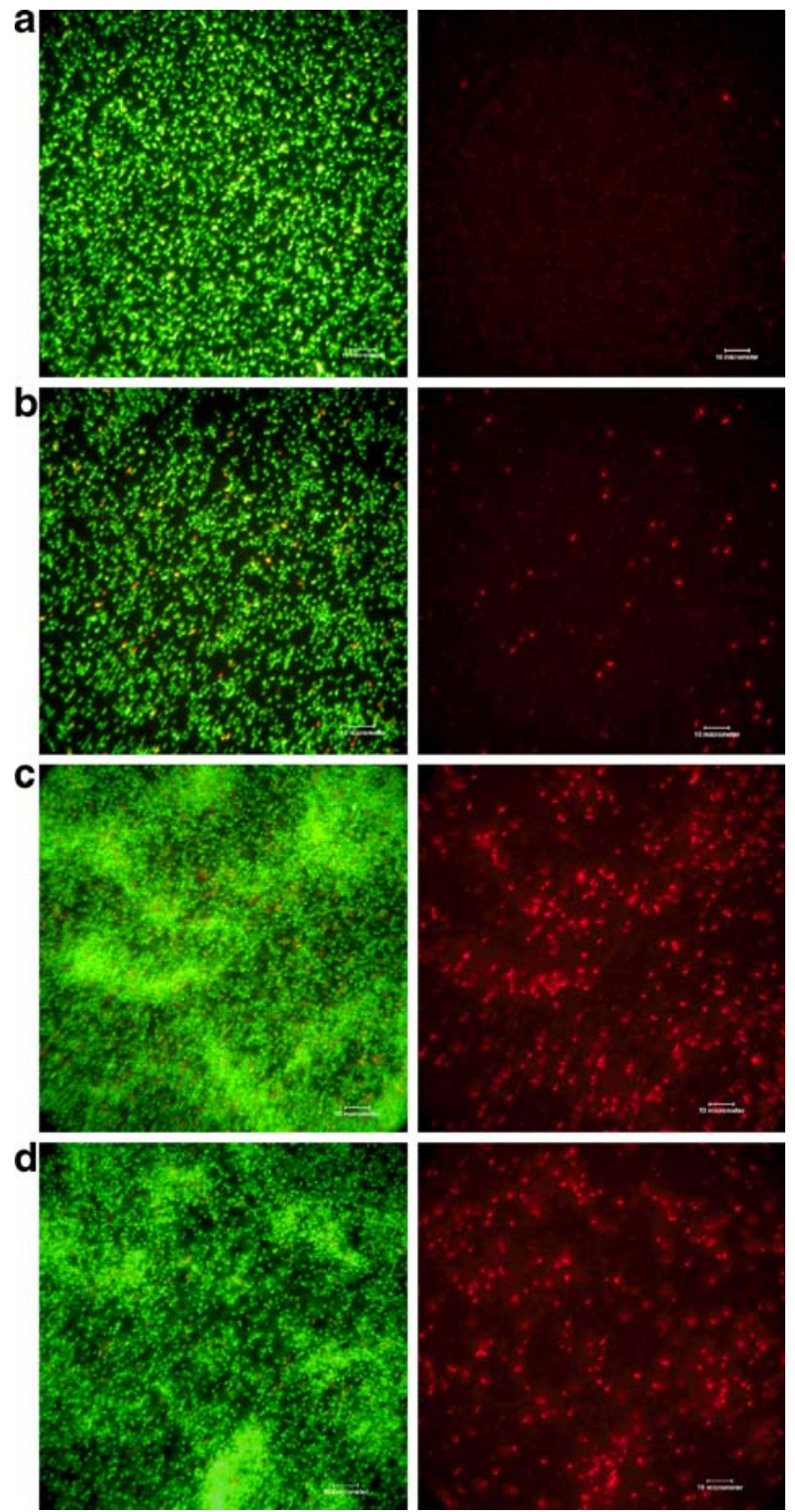
Fig. 4 (continued)
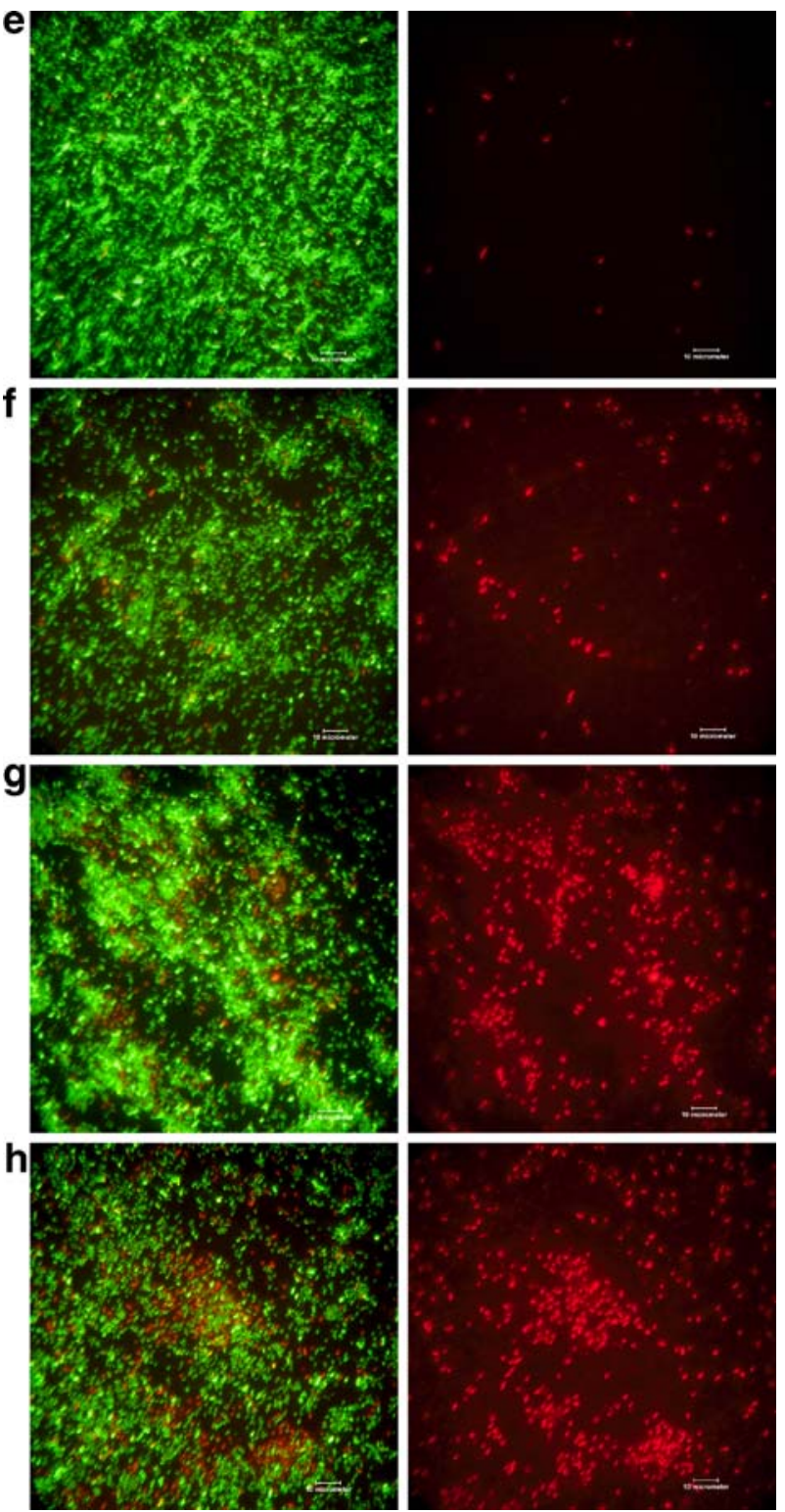

polymyxin B also showed activity against $M$. pachydermatis although the inhibitory concentration of the drug was higher than those against the bacteria tested.

As expected from the known antimicrobial spectrum of miconazole the fungizide was not inhibitory against the Gram-negative bacteria tested. Yet $S$. intermedius and the yeast $M$. pachydermatis were both susceptible at a MIC of 0.73 and $2.92 \mu \mathrm{g} / \mathrm{ml}$ respectively. These values are in agreement with corresponding studies who noticed concentrations of 0.1 to $10 \mu \mathrm{g} / \mathrm{ml}$ to be inhibitory against Gram-positive bacteria and many fungi including $M$. furfur (McEvoy 1992). With most of the sensitive fungi a MIC of 0.5 to $2.0 \mu \mathrm{g} / \mathrm{ml}$ was reported. However it should be kept in mind that the exactness of in vitro miconazole 

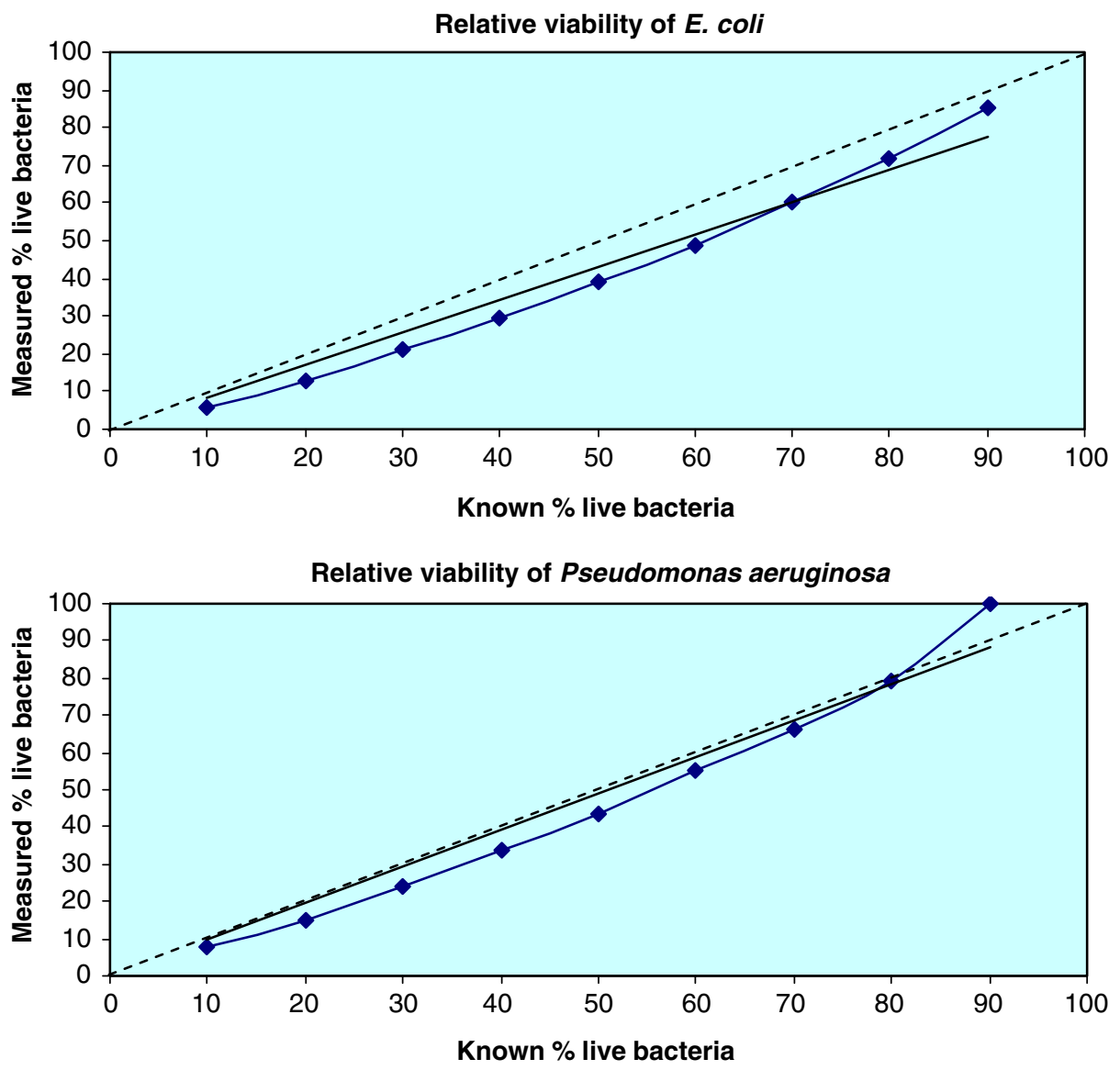

Fig. 5 Analysis of bacterial cells by flow cytometry. The known viability (proportion of 'live' to 'killed' bacteria) is plotted against the measured viability to identify the percent component of dead bacteria in the 'live' cell population

susceptibility testing depends on the measuring method and MIC values do not reflect the activity in vivo.

The MIC values derived from our tube dilution tests showed some variation. This may be due to the fact that cations such as $\mathrm{Mg}^{2+}, \mathrm{Al}^{3+}$, and $\mathrm{Ca}^{2+}$ can adversely affect the activity of antimicrobials. Several investigators have related increased resistance of $P$ aeruginos $a$ to aminoglycosides with increased concentrations of $\mathrm{Mg}^{2+}$ and $\mathrm{Ca}^{2+}$ in the media and conversely the antibacterial activity of aminoglycoside antibiotics was shown to be enhanced in media with low cationic content (D'Amato et al. 1975). Variations of these ions within lot-to-lot variation in Mueller-Hinton broth may be responsible for varying susceptibilities (Pollock et al. 1978). As well the activity of miconazole is affected by the medium composition as the effect of miconazole was notedly reduced even by very low concentrations of $\mathrm{Mg}^{2+}$ and $\mathrm{Ca}^{2+}$ cations (Sreedhara Swamy et al. 1974).

In CLSM analysis of drug action against $S$. intermedius we found a much higher dose of miconazole and polymyxin B to be necessary for a visual bactericidal effect. Presumably due to the thick cell wall of Gram-positive bacteria this strain reacted much slower to 

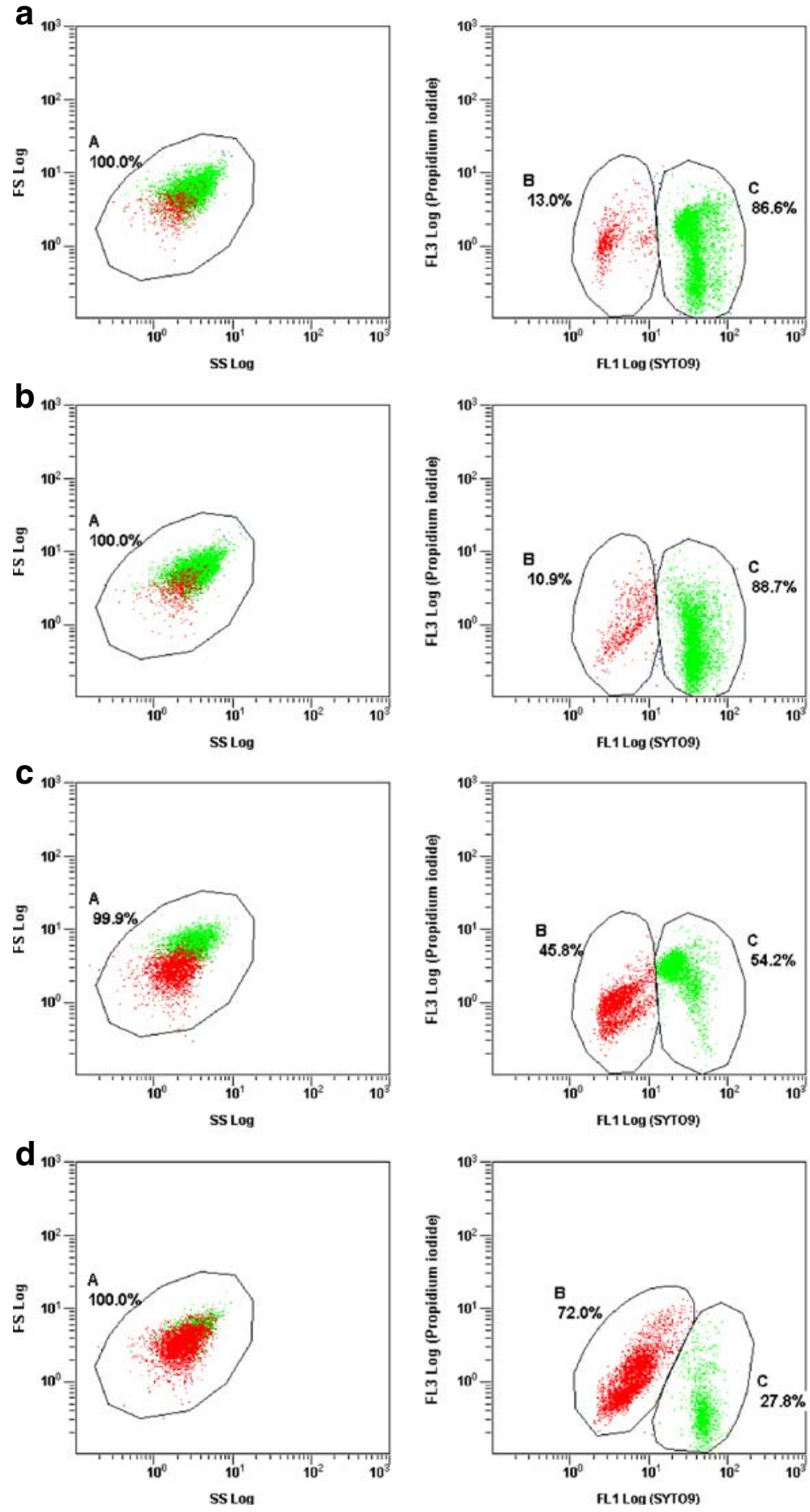
Fig. 6 Live/dead discrimination of $E$. coli after incubation with either polymyxin B, miconazol or both substances in combination for $18 \mathrm{~h}$. Cells were analysed by flow cytometry using a double colour staining consisting of SYTO9 and PI. Dot plots on the left show the whole cell populations, where green dots represent live cells and red dots denote dead cells. Dot plots on the right illustrate the bacterial populations separated into two regions $\mathrm{B}$ and $\mathrm{C}$ with $\mathrm{B}$ representing the dead cells (red, FL3), and C corresponding to the living cell population (green, FL1). Cells in B and $\mathrm{C}$ are displayed as $\%$ of the total population A. E. coli untreated (a), E. coli treated with $2,93 \mu \mathrm{g} / \mathrm{ml}$ miconazole (b), with $2.93 \mu \mathrm{g} / \mathrm{ml}$ polymyxin B (c), with $1.46 \mu \mathrm{g} / \mathrm{ml}$ miconazole plus $1.46 \mu \mathrm{g} / \mathrm{ml}$ polymyxin B (d)

miconazole and polymyxin B than Gram-negative cells and thus much higher drug doses were necessary to demonstrate a killing effect within $18 \mathrm{~h}$. On the other hand at the concentration, where a dilution of miconazole or polymyxin B caused bacteriostasis we detected only small differences in drug susceptibility between the Gram-positive and the Gram-negative bacteria.

The quantitative measurement of vital and dead cells after antibiotic action by means of flow cytometry was evaluated. When bacteria are treated with drugs that are assumed to change cell permeability this may also affect intracellular granularity and cell morphology and may encompass cell clumping as well. Measurement of antibiotic effects by flow cytometry detects such cellular changes through forward and side scatter. The loss of light scatter may delineate a change in cell size and could also represent a loss of cell wall constituents such as protein or RNA. This is likely to occur with the antibiotics used here. We found that regions are shifted after cells are exposed to polymyxin B and miconazole. Thus, for discrimination between live and dead cells we had to rearrange the regions after antibiotic exposure.

It was also noticed that miconazole at concentrations $>11 \mu \mathrm{g} / \mathrm{ml}$ a high percentage of $E$. coli cells stained red with PI (97.4\%) and $18.1 \%$ of $P$. aeruginosa cells became red after an identical dose of miconazole. Data from the tube dilution tests however demonstrated that this concentration of miconazole could neither inhibit growth of $E$. coli nor of $P$. aeruginosa. MBC assaying of those miconazole-exposed bacteria approved that the PIstained cells were all able to recover and to reproduce. Obviously under the condition of solitary miconazole application bacterial membranes are compromised allowing PI to penetrate into the cells and thus bacteria are falsely scored as dead in this assay. However, the lethal action is solely attained if miconazole is applied together with polymyxin $\mathrm{B}$. In accordance to the data above miconazole is known to change the membrane permeability at fungistatic concentrations (Sawyer et al. 1975, McEvoy 1992) while at fungicide concentrations the cell wall remains intact but intracellular compounds are destroyed (McEvoy 1992). As a result, the analysis of antimicrobial activity by flow cytometry or fluorescence microscopy using PI staining is possible although there are some restrictions concerning specific drugs such as miconazole, which may produce false results at certain concentrations. Consequently each drug to be analysed using this method should be pretested conducting precedent $\mathrm{MBC}$ testing on representative samples.

The combination of miconazole and polymyxin B produced synergistic inhibition of several germs at various in vitro conditions in our hands. On the basis of our data the antimicrobial activity of miconazole and polymyxin B was enhanced in all strains tested when both drugs are combined. Synergy refers to the phenomenon where the combination of drugs generates an effect that is greater than the sum of the effects produced by each of the components alone (Sabath 1968). This synergistic activity is related predominantly to the ability of polymyxin B to increase the penetration of hydrophobic antibiotics such as miconazole thus enabling miconazole to gain access to the intracellular space were it 
displays its lethal action. The results we obtained with the combination of miconazole and polymyxin B in all strains tested consistently showed a synergism of both drugs. Our results are in agreement with previous in vitro studies where a synergism of miconazole and polymyxin B was found for S. aureus, E. coli (Cornelissen and Van den Bossche 1983) and C. albicans Provided the in vitro antibacterial susceptibility predicts therapeutic response these data verify the potential for the use of combinations of the two antimicrobial agents in the topical treatment of infections caused by the prominent pathogenic microorganisms causative for otitis externa in dogs. The clear synergistic tendencies displayed by the twodrug combination allows for the reduction of the antibiotic concentrations, which minimizes toxicity and the probability of formation of resistances to these antibiotics. This may be of special interest in the case of $S$. intermedius which, ensuing antimicrobial therapy, is increasingly reported to be resistant to many antibiotics and failures in treatments cause problems in small animal practice. As a consequence the combination of both antimicrobials substantiates their clinical role in current formulations and offers a very effective therapeutic treatment.

Open Access This article is distributed under the terms of the Creative Commons Attribution Noncommercial License which permits any noncommercial use, distribution, and reproduction in any medium, provided the original author(s) and source are credited.

\section{References}

Booth, J.H., Benrimoj, S.I., Nimmo, G.R., 1994. In vitro interactions of neomycin sulfate, bacitracin, and polymyxin B sulfate. J Dermatol, 33, 517-520.

Cornelissen, F., Van den Bossche, H., 1983, Synergism of the antimicrobial agents miconazole, bacitracin and polymyxin B. Chemotherapy 29, 419-427.

Chambers, H.F, Antimicrobial Agents. In: Goodman and Gilman's The Pharmaceutical Basis of Therapeutics, 10th edition (Edited by: Hardman, J.G., Limbird, L.E. and Goodman Gilman, A.). McGraw-Hill Inc. 2001, 1239-1271.

D’Amato, R.F.C., Thornsberry, C., Baker, C.N., Kirven, L.A., 1975, Effect of calcium and magnesium ions on the susceptibility of Pseudomonas species to tetracycline, gentamicin, polymyxin B, and carbenicillin. Antimicrob Agents Chemother 7, 596-600.

Francois, I.E.J.A., Cammue, B.P.A., Borgers, M., Ausma, J., Dispersyn, G.D., Thevissen, K., 2006, Azoles: Mode of Antifungal Action and Resistance Development. Effect of Miconazole on Endogenous Reactive Oxygen Species Production in Candida albicans. Anti-Infect. Agents Med. Chem. 5, 3-13.

Hancock, R.E.W., 1984, Alterations in outer membrane permeability. Annu Rev Microbiol 38, 237-264. doi:10.1146/annurev.mi.38.100184.001321

Janssen, P.A.J., Van Bever, W.F.W., 1979, Miconazole. In:Pharmacological and Biochemical Properties of Drug Substances (Ed. by M.E. Goldberg). American Pharmaceutical Association, Washington, DC. 2, 333-354.

Junco, M.T.T., Barrasa, J.L.M., 2002, Identification and Antimicrobial Susceptibility of Coagulase Positive Staphylococci Isolated from Healthy Dogs and Dogs Suffering from Otitis Externa. J Vet Med B 49, 419-423. doi:10.1046/j.1439-0450.2002.00571.x

Kiss, G., Radvanyi, S., Szigeti, G., 1997, New combination for the therapy of canine otitis externa I Microbiology of otitis externa. J. Small Anim. Pract. 38, 51-56. doi:10.1111/j.1748-5827.1997.tb02987.x

Kobayashi, D., Kondo, K., Uehara, N., Otokozawa, S., Tsuji, N., Yagihashi, A., and Watanabe, N.A.A.C., 2002, Endogenous Reactive Oxygen Species Is an Important Mediator of Miconazole Antifungal Effect. Antimicrob. Agents Chemother. 46, 3113-3117. doi:10.1128/AAC.46.10.3113-3117.2002

Koike, M., Iida, K., Matsudo, T., 1968, Electron microscopic studies on mode of action of polymyxin. J Bacteriol 97, 448:452.

Kucers, A., 1997, Polymyxins. In: Kucers, A., Crowe, S., Grayson, M.L., eds. The Use of Antibiotics: A Clinical Review of Antibacterial, Antifungal, and Antiviral Drugs. 5th edn. Oxford: ButterworthHeinemann, 667-675. 
Leeming, J.P., Notman, F.H., 1987, Improved methods for isolation and enumeration of Malassezia furfur from human skin. J Appl Bacteriol 67, 47-52.

McEvoy, G.K., 1992, American Hospital Formulary Service - Drug Information. American Society of Hospital Pharmacists Inc, Bethesda (USA), 2363.

Moneib, N.A., 1995, In-vitro activity of commonly used antifungal agents in the presence of rifampin, polymyxin B and norfloxacin against Candida albicans. J Chemother 7, 525-529.

Nakamura, Y., Kano, R., Murai, T., Watanabe, S., Hasegawa, A., 2000, Susceptibility Testing of Malassezia Species Using the Urea Broth Microdilution Method. Antimicrobial Agents and Chemotherapy 44, 2185:2186.

Newton, B.A., 1953, Reversal of the antibacterial activity of polymyxin by divalent cations. Nature 172 , 160-161. doi:10.1038/172160a0

Newton, B.A., 1954, Site of action of polymyxin on Pseudomonas aeruginosa: antagonism by cations. J Gen Microbiol 10, 491:499.

Nikaido, H., Vaara, M., 1985, Molecular basis of bacterial outer membrane permeability. Microbiol Rev 49, $1-32$.

Odds, F.C., 2003. Synergy, antagonism, and what the chequerboard puts between them. J Antimicrob Chemother 52:1. doi:10.1093/jac/dkg301

Ouderkirk, J.P., Nord, J.A., Turett, G.S., Kislak, J.W., 2003, Polymyxin B nephrotoxicity and efficacy against nosocomial infections caused by multiresistant Gram-negative bacteria. Antimicrob Agents Chemother 47, 2659-2662. doi:10.1128/AAC.47.8.2659-2662.2003

Pasquale, T.R., Tan, S.R., 2005, Update on antimicrobial agents: new indications of older agents. Expert Opin Pharmacother 6, 1681-1691. doi:10.1517/14656566.6.10.1681

Pollock, H.M., Minshew, B.H., Kenny, M.A., Schoenknecht, F.D., 1978, Effect of Different Lots of MuellerHinton Agar on the Interpretation of the Gentamicin Susceptibility of Pseudomonas aeruginosa. Antimicrob Agents Chemother 14, 360-367.

Richards, R.M., Xing, D.K., 1993, Investigation of synergism between combinations of ciprofloxacin, polymyxin, sulphadiazine and p-aminobenzoic acid. J Pharm Pharmacol 45, 171-175.

Rincón, S., Cepero de García, M.C., Espinel-Ingroff, A., 2006, A Modified Christensen's Urea and CLSI Broth Microdilution Method for Testing Susceptibilities of Six Malassezia Species to Voriconazole, Itraconazole, and Ketoconazole. J Clin Microbiol 44, 3429:3431.

Roberts, G.D., Horstmeier, C.D., Land, G.A., Foxworth, J.H., 1978, Rapid urea broth test for yeasts. J Clin Microbiol 7, 584-588.

Rosenthal, K.S., Storm, D.R., 1977, Disruption of the Escherichia coli outer membrane permeability barrier by immobilized polymyxin B. J Antibiot (Tokyo) 30, 1087-1092.

Rougier, S., Borell, D., Pheulpin, S., Woehrle, F., Boisrame, B., 2005, A comparative study of two antimicrobial/anti-inflammatory formulations in the treatment of canine otitis externa. Vet. Dermatol. 16, 299-307. doi:10.1111/j.1365-3164.2005.00465.x

Sabath, L.D., 1968, Synergy of antibacterial substances by apparently known substances. Antimicrob Agents Chemother 8, 210-217.

Sawyer, P.R., Brogden, R.N., Pinder, R.M., Speight, T.M., Avery, G.S., 1975, Miconazole: a review of its antifungal activity and therapeutic efficacy. Drugs 96, 406-423. doi:10.2165/00003495-197509060-00002

Schwartz, S.N., Medoff, G., Kobayashi, G.S., Kwan, C.N., Schlessinger, D., 1972, Antifungal properties of polymyxin B and its potentiation of tetracycline as an antifungal agent. Antimicrob Agents Chemother 2, 36-40.

Sreedhara Swamy, K.H., Sirisi, M., Ramananda Rao, G., 1974, Studies on the mechanism of action of miconazole: Effect of miconazole on respiration and cell permeability of Candida albicans. Antimicrob Agents Chemother 5, 420-425.

Studdert, V.P., Hughes, K.L., 1991, A Clinical-Trial of a Topical Preparation of Miconazole, Polymyxin and Prednisolone in the Treatment of Otitis-Externa in Dogs - Reply. Aust. Vet. J. 68, 313-314. doi:10.1111/ j.1751-0813.1991.tb03275.x

Vaara, M., 1992, Agents that increase the permeability of the outer membrane. Microbiological Rev 56, 395-411.

Vanden Bossche, H., Cornelissen, F., Van Cutsem, J., 1982, Synergism of the antimicrobial agents miconazole and benzoylperoxide. Brit J Dermatol 107, 343-348. doi:10.1111/j.1365-2133.1982. tb00365.x

Vanden Bossche, H., Marichal, P., Willemsens, G., Bellens, D., Gorrens, J., Roels, I., Coene, M.C., Le Jeune, L., Janssen, P.A.x., 1990, Saperconazole: a selective inhibitor of the cytochrome P-450-dependent ergosterol synthesis in Candida albicans, Aspergillus fumigatus and Trichophyton mentagrophytes. Mycoses 33, 335-352.

Warren, G.H., Gray, J., Yurchenco, J.A., 1957, Effect of polymyxin on the lysis of Neisseria catarrhalis by lysozyme. J Bacteriol 74, 788-793. 